\title{
Improvement of Self-regulation to Reduce Externalizing Behavior Problems in Juvenile Prisoners
}

\begin{abstract}
Rifdha W. Darmis*, T. Winarsunu and M.S. Yuniardi
Abstract--- Externalizing behavior problems (EBP) are harmful actions that may distract or harm other people, which includes disobedience, aggression, hyperactivity, impulsive behavior, disruptive behavior, rule violation, and property damage. One of the factors to reduce the EBP is the ability to perform self-regulation. This skill relates to the individual response according to the situational context. This study aims at finding out the effect of selfregulation improvement towards the EBP of juvenile prisoners. The subject of this study were twenty juvenile prisoners (age range 12-18 years old) in two groups, namely experimental and control groups. The experimental group received a self-regulation group therapy to increase the subject's self-regulation, while the control group did not go through the treatment. This study applied the Youth Report Form (YRF) and Adolescent Self Regulation Inventory (ASRI-A) scales. The data analysis used a non-parametric type, namely Mann Whitney, Wilcoxon, and Kendall Correlation tests. The result of the study shows there is a negative effect of self-regulation towards the EBP of juvenile prisoners.
\end{abstract}

Keywords--- Self-regulation, Externalizing Behavior Problems, Juvenile Prisoners, Group Therapy.

\section{INTRODUCTION}

Externalizing Behavior Problems (EBP) are negative actions that harmful for other people which includes disobedience, aggression, hyperactivity, impulsive behavior, disruptive behavior, rule violation, and property damage. ( ${ }^{1}$ Achenbach \& Edelbrock, 1978; ${ }^{2}$ Jenson, Harward, \& Bowen, 2011). EBP is a symptom of classification systems of disruptive, impulse-control, and conduct disorder on DSM-V $\left({ }^{3} \mathrm{APA}, 2013\right)$. A severe EBP increases the potential to involve in crime and anti-social, which eventually leads to emotional and other behavioral disorders $\left({ }^{4}\right.$ Karaman, 2013). EBP acts to form mal-adaptive behavior and have the potential to lead to mental disorder $\left({ }^{5}\right.$ Olson et al., 2005).

EBP can also relate to mental issues marked by maladaptive behavior, which aims at the environment resulting in damage or disorders in running other life functions ( ${ }^{6}$ Eisenberg et al., 2001). The situation is different from the internalizing behavior problem where maladaptive cognition and emotion aim at onself $\left({ }^{7}\right.$ Krueger, Markon, Patrick, \& Iacono, 2005).

The manifestation of EBP behavior is in the form of antisocial and aggressive behaviors by opposing the authority, social norms, and other people's rights. EBP can result in detrimental consequences for the individual and other people. The examples of EBP symptoms are loss of patience, excessive verbal aggression, physical aggression

Rifdha W. Darmis*, Muhammadiyah University of Malang, East Java, Indonesia. Email: rfd.wahyuni@gmail.com

T. Winarsunu, Muhammadiyah University of Malang.

M.S. Yuniardi, Muhammadiyah University of Malang. 
towards humans and people, property destruction, theft, and deliberate play of fire that causes problems. EBP must receive a proper treatment when functional disorder appears on one of the domains, such as academic skill, occupation, social, or family (APA, 2013). Besides that, it is necessary to prove that the individual symptom must be unique and following the cultural context and environment, as well as physical condition, must not be taken as any consideration during the diagnose attempt $\left({ }^{8}\right.$ Hinshaw \& Beauchaine, 2015; ${ }^{9}$ Liu, 2004).

In previous study, there was a finding stated that problem behavior had a strong effect on self-regulation skills $\left({ }^{10}\right.$ Eiden, Edwards, \& Leonard, 2007). Another finding supports this claim stating that a child with EBP had issues with self-regulation skills in terms of his emotion, cognition, and behavior $\left({ }^{11}\right.$ Graziano et al., 2015 ; ${ }^{12}$ Jonas \& Kochanska, 2018). Self-regulation in a child has emerged during the pre-natal phase to the relatively-stable situation in the pre-school stage; still in the meantime, on the development process, this condition is more affected by environmental factors related to the behavior origin of support taken by the child ( ${ }^{13}$ Moilanen, 2007).

The emergence of EBP on teenagers is the result of an unbalance between a high motivation drive and a low level of self-control in teenagers, which eventually increases the risk of behavioral contribution $\left({ }^{14}\right.$ Steinberg, 2010$)$. Based on the result of the study, teenagers who involve in drug abuse is mostly due to their low level of self-control. The situation ignites negative emotion, low motivation, and receives strong support by maladaptive peer environment. The negative emotion is a product of the low level of self-regulation as an initial manifestation of aggressive behavior and antisocial in the future $\left({ }^{15}\right.$ Rothbart et al., 1994; ${ }^{16}$ Rothbart et al., 2015; ${ }^{17}$ Spinrad et al., 2015).

Youth who can easily involve in the harmful activity for both him/herself and the environment indicates the existence of a problem in self-regulation in proper ways or in a way that is socially acceptable $\left({ }^{18} \mathrm{Calkins} \&\right.$ Fox, 2002; ${ }^{19}$ Campbell, Shaw, \& Gilliom 2000). The issues usually occur to the youth that involve in law cases, causing different life experience compared to average teenagers. The previous study explains that low self-regulation identic with a high potential occusrence of behavioral problems such as externalization and internalization during childhood and adolescence. The connection consistently is revealed in researches related to antisocial and juvenile delinquents, drugs abuses, hostility, rudeness, and aggression $\left({ }^{20}\right.$ Brody \& Ge, 2001; ${ }^{21}$ Eisenberg et al., 2005; ${ }^{22}$ Finkenauer, Engels, \& Baumeister, 2005; ${ }^{23}$ Tangney, Baumeister, \& Boone, 2004; ${ }^{24}$ Vazsonyi et al., 2001).

Self-regulation involves skills mastery of initiating, avoiding, inhibiting, maintaining, or the changing process of an event, form, intensity, or duration of an internal feeling, emotional physiology, attentional process, motivation, and /or simultaneously with the emotion. These attempts are efforts to achieve biological and social adaptations related to the way or strategies of individuals in achieving their goals. ( ${ }^{25}$ Eisenberg \& Spinrad, 2004). This selfregulation develops from time to time through a transactional process based on the rules or norms that apply, the maturity of the executive function, and is influenced by educational experience and the social environment such as at school, family, and peers. $\left({ }^{26}\right.$ Rothbart \& Ahadi, 1994; ${ }^{27}$ Rueda, Rothbart, \& Posner, 2005; ${ }^{28}$ Wills \& Dishion, 2004).

Self-regulation has two crucial aspects. First, short-term self-regulation that focuses on controlling impulses and managing short-term desires. Individuals with low impulse control tend to act on direct desires, and this condition is 
more common in criminal offenders. Whereas for those not involved in criminal cases, low short-term selfregulation can cause easy loss of friends due to uncontrolled emotional outbursts or financial problems caused by impulsive behavior. (Rueda, Rothbart, \& Posner, 2005; Moilanen, 2007).

Second, long-term self-regulation is the ability to act following long-term interests and is consistent with their values. Violation of one's values will lead to consequences in the form of guilt, shame, and anxiety which will ultimately damage the welfare (Rueda, Rothbart, \& Posner, 2005; Moilanen, 2007).

One way to overcome EBP in youth is to improve self-regulation $\left({ }^{29}\right.$ Eisenberg, $2017 ;{ }^{30}$ Purwono, French, Eisenberg, \& Christ, 2018); therefore, it can reduce the EBP level. The method that can be used is to involve individuals in self-regulation group therapy where the subjects are involved in groups that have the same problem and then motivate each other to achieve goals, both individuals and groups. The main goal of this therapy is to help individuals achieve a better understanding of themselves so they can find self-concepts, express needs, express reactions to the pressures they experience and can develop positive emotions $\left({ }^{31}\right.$ Corey, 2013).

The therapeutic process will teach the group to look at a person's life in a moving situation, which is a way of feeling what is happening and what is not happening in a particular situation. This therapy will also involve roleplaying to display certain events or events, aiming to get a new view of an event and encourage the group to conduct a process of self-assessment of the behavior displayed. The representation shown can bring a new perspective to other actors or viewers who might see themselves reflected in the scenes shown or efforts to express something. Each group member in this therapy is a therapeutic agent for each other so that the events displayed can be a healing practice for each member. $\left({ }^{32}\right.$ Karp, Holmes, \& Tauvon, 1998).

Based on the discussion above, it appears that self-regulation has a strong influence on EBP. The idea put forward in this study is that if self-regulation can be improved, EBP will go down. Researchers use Self-Regulation Group Therapy to improve self-regulation by targeting improvements in self-recognition and understanding, the ability to conduct self-evaluation and plan, and arrange strategies to achieve future goals $\left({ }^{33}\right.$ Bandura et al., 2003;

${ }^{34}$ Baumeister \& Vohs, 2011). Therefore, researchers want to focus on efforts to improve self-regulation to reduce EBP in juvenile prisoners. The purpose of this study is to determine the effect of self-regulation on EBP.

\section{EXPERIMEntal, MATERIAls ANd Methods}

\subsection{Experimental}

The research design used was the pretest-post-test control group experiment. $\left({ }^{35}\right.$ Kelinger, 1996). This design used one experimental group (getting self-regulation group therapy) and one control group (not given treatment). Before and after treatment in both groups, there were measurements on increasing self-regulation and decreasing externalizing behavior problems. The treatment in the form of self-regulation group therapy aims at forming the selfregulation. A manipulation check is a tool to determine the effectiveness of the therapy. $\left({ }^{36}\right.$ Hauser, Ellsworth, \& Gonzalez, 2018).

This research was in groups of juvenile prisoners. The first thing to do is to pre-evaluation research by piloting. The aim is to adapt the measuring instrument to the participant's understanding and culture. Second, dividing the 
research subject into two groups, namely the experimental group and the control group. The distribution is done randomly by a lottery system. Manipulation was given to the experimental group in the form of self-regulation group therapy, while the control group did not get any treatment. Third, the researcher conducted a group matching, where before holding the experiment, the researcher saw a match between the pretest scores of the experimental group and the control group in order to achieve a balance. The purpose of group matching is to equalize the initial conditions between groups so that both groups have a similar condition before being given an intervention.

Fourth, the researcher asked for approval from the participants of the experimental group to follow the therapy process from beginning to end. The treatment given to the experimental group was self-regulation group therapy with six sessions in approximately one month. Fifth, carry out the first stage of intervention, namely rapport building, building commitment to each subject involved, and conducting initial assessments. Sixth, run the second intervention stage. The intervention consisted of introductions in the group, an explanation of self-regulation in adolescents, self-exploration, developing the ability to empathize, building expectations (positive emotions), evaluation. Seventh, carry out the third intervention stage: Post-intervention, which is conducting a final assessment to check subject changes.

\subsection{Materials}

There are two scales used in this study. P First, the Youth Report Form (YRF) developed by ${ }^{37}$ Thomas M. Achenbach (1991) aims to measure externalizing behavior problems in youth. The reliability of this instrument based on the Cronbach alpha value is 0.90 . Second, the scale of Adolescents Self Regulation Inventory (ASRI), which measures self-regulation with the dimensions of short-term self-regulation and long-term self-regulation. This scale was developed by Moilanen (2007). Reliability of the instrument based on Cronbach's alpha values were 0.84 and 0.72 .

\subsection{Methods}

The subjects used in this study were 20 juvenile prisoners who were trained in the Correctional Facility for Children (LPKA) Class IIB Tanjung Pati and fulfilled the characteristics prepared by researchers. Subjects were taken using a simple random sampling technique.

Characteristics of the subjects are prisoners who are fostered in Juvenile Correctional Facility with a range of ages 12-18 years, where at that age individuals are in the stages of early adolescence to intermediate $\left({ }^{38}\right.$ Hurlock, 2012). Gender male and never married. The minimum level of education is graduating elementary school (SD), where respondents can read, write, and have the ability to think abstractly following Piaget's stages of cognitive

development. The youth are at the formal operational stage. $\left({ }^{39}\right.$ Santrock, 2012). The cases where youth involvement referring to juvenile delinquents are in the form of brawls, mild or severe maltreatment, theft, and property damage. Have the remaining sentence to complete for a maximum of 2 years. Not under the influence of drugs and the like. Do not have a history of consuming drugs for a long time in good health, both physically and mentally.

\subsubsection{Pre-evaluation Research}

This study uses piloting as an initial evaluation of the research instruments used in several raters and non-control and experimental subjects that have been predetermined. Moser and Kalton (1992) define piloting as a rehearsal 
before conducting actual research where researchers have the opportunity to ask questions directly related to the effectiveness of the language on each item questionnaire used. Its function is to identify and minimize errors in the source of measurement, which in this case, is a measurement instrument that can cause errors due to language understanding. The pilot trial process and instrument feasibility underwent an exploration, which then became the basis of improvements mechanism before starting the actual research study $\left({ }^{41}\right.$ Grinnell \& Unrau, 2011). In other words, piloting is an item readability test process.

Piloting was conducted on ten raters with experience dealing with juvenile delinquency and 20 non-experimental and control group subjects. The result is that for the Youth Report Form (YRF) instrument with 41 items, there are changes in 2 items, items 4 and 23. The Instrument Adolescents Self Regulation Inventory (ASRI), which measures short term self-regulation with 13 items changes in 5 items, namely items $6,8,16,17$, and 21 . On the other hand, the aspects of long-term self-regulation with 13 items have changed in 3 items, namely items 28, 30, and 31 .

\subsubsection{Data Analysis}

The results of the obtained data underwent the analysis process using SPSS 21.0 to see improvements, differences, and effects of previous experiments. The analysis was by comparing the results of the initial conditions before and after the intervention is given. The aim is to find out the increase in self-regulation ability, which then aimed at reducing the EBP in juvenile prisoners. The statistical analysis used was non-parametric statistical Mann Whitney U test, Wilcoxon test, and Kendall Tau-b Correlation test, due to the small sample $\left({ }^{42}\right.$ Seniati, Yulianto, \& Setiadi, 2005). Mann Whitney U test aims to see differences in each group, while the Wilcoxon test aims to see differences in the results of the pretest and posttest. Kendall Correlation Test aims to see the effect of increasing self-regulation on decreasing externalizing behavior problems after the intervention is given to participants in the experimental group.

\section{RESULT AND DISCUSSION}

\subsection{Results}

\subsubsection{Manipulation Check}

Before carrying out the manipulation check, there was a homogeneity test for each variable to determine whether the group has the same initial conditions before being given treatment. The results of the homogeneity test show that each group has the same initial or homogeneous conditions, indicated by the Sign value. each variable is above 0.05 (Self regulation $=0.560$ and $\mathrm{EBP}=0.356$ ). It can be concluded that the data variance of each variable in the experimental and control groups is homogeneous.

Mann Whitney Test Results on self-regulation with the coefficient of Mann Whitney U is 41,000 $(Z=-4,310)$ with a p-value of 0,000 with a significance of $p<0.05$. Then, the researcher conducts an analysis based on aspects of self-regulation to deepen the results of the study. The short-term aspect of self-regulation has a Mann Whitney $U$ coefficient of $6,000(Z=-3,364)$ with a p score of 0.001 , where $p<0.05$ (probability value). |On the other hand, the long-term aspect of self-regulation has a correlation value of the Mann Whitney $U$ test coefficient of $0,000(Z=-$ 
3,784 ) with a $\mathrm{p}$ score of 0,000 , where $\mathrm{p}<0.05$ (probability value), then, based on post-test scores, it can be concluded that there are significant differences in self-regulation between the experimental and control groups.

Wilcoxon test results on the self-regulation variable showed that in the experimental group, the results of the posttest score of self-regulation were more significant than the pretest score. Similarly, it appears in both aspects of self-regulation. The condition means that there was a significant increase in self-regulation scores in the experimental group after there was treatment to improve self-regulation, whereas the control group obtained no significant results on the self-regulation variable. These results explain that in the control group, there were no significant changes in the pretest and posttest scores of self-regulation.

Therefore, we can conclude that the overall, there are differences in the score of self-regulation in the experimental group compared to the control group. The situation causes manipulation, namely Self-Regulation Group Therapy, which has been proven effective in increasing the ability to self-regulate in the experimental group.

\subsubsection{Hypothesis Test}

The connection between self-regulation variables and EBP, this study used Kendall Tau-b correlation. This process carried out the experimental group. Kendall Tau-b test results found that the correlation coefficient value of the self-regulation variable against EBP was -0.452 with a p-value of 0.007 ( $p<0.05)$. That is, the self-regulation variable significantly has a relatively close negative relationship with the EBP variable so that the higher the ability to self-regulate, the lower the EBP in adolescent prisoners. This finding proves that the hypothesis that there is a negative effect of self-regulation on EBP adolescent prisoners is accepted.

Then, to deepen the results of the study conducted an analysis based on aspects. The short-term aspect of selfregulation has a relatively close and significant adverse effect on EBP of - 0.433 , while the aspect of long-term selfregulation has a substantial and significant adverse effect on EBP of - 0, 533.

Wilcoxon test results on the EBP variable showed that the experimental group obtained an average posttest on the EBP scale $(M=42.0 ; S D=4.62)$ smaller than the mean value of the pretest $(M=53.1 ; S D=9,02)$. That is, there was a significant decrease in the EBP score of the experimental group after there was an increase in selfregulation $(\mathrm{p}<0.05)$, while the results of the analysis in the control group showed no significant difference in the pretest and posttest scores.

Based on the analysis, we can conclude that the hypothesis stating there is a negative influence of short-term self-regulation and long-term self-regulation on EBP in adolescent prisoners. Therefore, the hypothesis that there is a negative effect of self-regulation on EBP adolescent prisoners is accepted. That is, the higher the self-regulation of a teenager, the lower the EBP it has. Improved self-regulation is a result of self-regulation group therapy given to the experimental group.

\subsection{Discussion}

Based on the analysis, we can conclude that the hypothesis stating there is a negative influence of short-term self-regulation and long-term self-regulation on EBP in adolescent prisoners. Therefore, the hypothesis that there is a negative effect of self-regulation on EBP adolescent prisoners is accepted. That is, the higher the self-regulation of 
a teenager, the lower the EBP it has. Improved self-regulation is a result of self-regulation group therapy given to the experimental group.

The results of this study are following previous research, which states that increased ability to control oneself both related to controlling thoughts, feelings, and behavior can reduce the emergence of maladaptive behaviors such as naughty behavior in adolescents. ${ }^{43}$ (Piquero et al., 2016). The intervention given in the study of Piquero et al. (2016) involved discussion groups consisting of children who have problems with the law. The focus is to increase the ability to understand emotions and communicate them well, the ability to make friends, the ability to control oneself, and the ability in social problem-solving. Besides, it also has given an understanding of maladaptive behaviors in the form of psychoeducation. The results show that an increase in the ability to self-regulate occurs by $7.2 \%$, and a decrease in delinquency behavior occurs by $3.7 \%$.

Likewise, in this study, the contribution of the aspect of short-term self-regulation to the reduction in EBP was $43.3 \%$. This result is lower than the contribution shown by the aspect of long-term self-regulation that is equal to $53.3 \%$. That is, the subject can understand well the mistakes they have made and try to control themselves so as not to confront them again with legal issues. However, due to the process of adjusting to the environment and culture of prisoners, the daily self-regulation process still needs to be trained. Teenagers with a background law violation will learn to avoid the same situation in the past so that the ability to analyze problems will increase. This condition can have both good and bad effects because this change process also involves prisoners' efforts to adjust to the prisoner's environment. $\left({ }^{44}\right.$ Clemmer, 2006; ${ }^{45}$ Roberton, Daffren, \& Bucks, 2014).

Skill development in self-regulation has a significant effect on social life. One of the attempts to improve social life is through self-training to behave according to the prevailing norms and values in the social environment on a regular basis. Training that involves all elements, both related to cognition, emotions, and physical (behavior), gives maximum results. ( ${ }^{46}$ Baumeister, Gailliot, DeWall, \& Oaten, 2006). Motivation to change oneself has become the main factor that determines the success of this study. This condition allows the individual to be able to follow what the environment expects rather than follow the impulse in themselves that is destructive. The training that is given regularly by reinforcing understanding of daily life has proven to be useful as a way to suppress negative impulses from within.

Besides, the feeling of the same fate and struggle in the face of punishment makes the relationship between subjects stronger. Naturally, the subject has pushed himself to show good behavior during the rest of the sentence. The subject realized that it needed preparation to deal with the outside environment and be able to adapt in more positive ways. Therefore, they need regular training to help individuals understand themselves better concerning cognition, emotions, and behavior $\left({ }^{47}\right.$ Gullota \& Adams, 2005).

Efforts to improve the ability that comes from within oneself that acts as a filter when in the social environment can reduce the intensity and frequency of appearance of EBP behavior. Adolescents who are dealing with the law or who are involved in juvenile delinquency come from pathological environments, one of which has a family environment that is not conducive $\left({ }^{48}\right.$ Gardner, Dishion, \& Connell, 2008). This study's finding shows that general 
juvenile prisoners come from families that are not intact so that throughout their lives do not get a good understanding of where good and bad behavior, the risks, and not trained in solving problems.

Based on previous research found in the intermediate to late adolescents, self-regulation acts as a resilience factor in protecting adolescents from negative influences and peer abuse. These results indicate that interventions that target the ability of self-regulation can be a preventive effort to improve the risk of developing behavioral problems becoming worse in the future, such as experiencing antisocial behavior problems (Gardner, Dishion, \& Connell, 2008).

The research finding strengthens less comprehension towards harmful emotion, thoughts, and behavior, both to oneself (internalization) and external aspects (externalization) have become significant components for the intervention program. The individual approach before the intervention is given in groups has a significant impact on the success of the intervention program. $\left({ }^{49}\right.$ Dane \& Marini, 2014). There is a need to get an agreement with the subject to follow the intervention program involuntarily and help individual subjects bring up the motivation for self-change for the better.

This research has a limitation; that is, researchers have difficulty in creating conducive situations and conditions while providing treatment to the experimental group. The limitation is due to the condition of the prison building, which is occupied by women, young women, and men fostered residents. Besides, the implementation of an intervention program involving ten subjects occurred in an open space, with many fostered residents paying attention to the process carried out. This condition did not enter into the consideration of previous researchers so that in the initial program implementation, it was quite challenging to control the situation. The finding causes the inability to achieve maximum changes in the subjects; therefore, a solution to this issue will result in a better situation. As a suggestion for further study, it is necessary to conduct a rehearsal and material test for the venue of the research to consider the barriers that might appear during the intervention. Besides, the researcher also suggests involving several experienced observer teams in dealing with juvenile prisoners to consider the changes that might require an in-depth observation.

\section{REFERENCES}

[1] Achenbach, T., \& Edelbrock, C. J. (1978). The classification of child psychopatology: a review and analysis of empirical effort. Psychological Bulletin, 85 (85), 1275 - 1301.

[2] Jenson, W. R., Harward, S., \& Bowen, J. M. (2011). Externalizing disorders in children and adolescents: behavioral excess and behavioral deficits. Journal of Social Psychology, 141 (13), 1 - 59.

[3] American Psychiatric Association. (2013). Diagnostic and Stastical Manual of Mental Health Disorder Edition (DSM-V). Washington D.C: American Psychiatric Publishing.

[4] Karaman, N. G. (2013). Predicting the problem behavior in adolescents. Eurasian Journal of Educational Research, (52), 137-154.

[5] Olson, S. L., Sameroff, A. J., Kerr, D. C. R., Lopez, N. L., \& Wellman, H. M. (2005). Developmental foundations of externalizing problems in young children: the role of effortful control. Developmental and Psychology, 17 (0), $25-45$.

[6] Eisenberg, N., et. al. (2001). The relations of regulation and emotionality to children's externalizing and internalizing problem behavior. Child Development, 72 (4), $1112-1134$.

[7] Krueger, R. F., Markon, K. E., Patrick, C. J., \& Iacono, W. G. (2005). Externalizing psychopatology in adulthood: a dimensional - spectrum conceptualization and it's implication for DSM-V. Journal of Abnormal Psychology, 114 (4), 537 - 550. 
[8] Hinshaw, S. P., \& Beauchaine, T. P. (2015). The developmental psychopatology perspective on externalizing behavior dimensions and externalizing disorders. Psychology, Cognitive Neuroscience, Clinical Psychology, Online Pub, 90 - 104.

[9] Liu, J. (2004). Childhood externalizing behavior: theory and implications. Journal of Child and Adolescent Psychiatric Nursing, 17 (3), $93-103$.

[10] Eiden, R. D., Edwards, E. P., \& Leonard, K. E. (2007). A conceptual model for the development of externalizing behavior problems among kindergarten children of alcoholic families: role of parenting and children's self-regulation. Journal of Development Psychology, 43 (5), 1187 - 1201.

[11] Graziano, P. A., Slavec, J., Ros, R., Garb, L., Hart, K., \& Garcia, A. (2015). Self-regulation assessment among preschoolers with externalizing behavior problems. Psychological Assessment, 27(4), 1337-1348.

[12] Jonas, K., \& Kochanska, G. (2018). An imbalance of approach and effortful control predicts externalizing problems: support for extending the dual-systems model into early childhood. Journal of Abnormal Child Psychology, 1-11.

[13] Moilanen, K. L. (2007). The adolescent self-regulatory inventory: the development and validation of a questionnaire of short-term and long-term self-regulation. Journal of Youth and Adolescence, 36 (6), $835-848$.

[14] Steinberg, L. (2010). A dual systems model of adolescent risk-taking. Developmental Psychobiology, 52 (3), $216-224$.

[15] Rothbart, M. K., \& Ahadi, S. A. (1994). Temperament and the development of personality. Journal of Abnormal Psychology, 103 (1), 55 - 66.

[16] Rothbart, M. K., Ahadi, S. A., \& Hershey, K. L. (2015). Temperament and social behavior in childhood. Merrill-Pamer Quarterly, 40 (1), 21 - 39.

[17] Spinrad, T. L., \& Eisenberg, N. (2015). Relations with emotion regulation, adjustment and socialization in childhood. In Emerging Trends in The Social and Behavioral Sciences, 18 (1), 1 - 11.

[18] Calkins, S. D., \& Fox, N. A. (2002). Self-regulatory processes in early personality development: a multilevel approach to the study of childhood social withdrawl and aggression. Journal of Development Psychology, 14 (3), 477 - 498.

[19] Campbell, S.B., Shaw, D.S., \& Gilliom, M. (2000). Early externalizing behavior problems: toddlers and preschoolers at risk for later maladjustment. Development and Psychopathology, 12, 467 - 488.

[20] Brody, G. H., \& Ge, X. (2001). Linking parenting processes and self-regulation to psychological functioning and alcohol use during early adolescence. Journal of Family Psychology, 15 (1), 82 - 94.

[21] Eisenberg, N., Zhou, Q., Spinrad, T. L., Valiente, C., Fabes, R. A., \& Liew, J. (2005). Relations among positive parenting, children's effortful control, and externalizing problems: a three-wave longitudinal study. Journal of Child Developmental Psychology, 76 (5), 1055 - 107.

[22] Finkenauer, C., Engels, R. C. M. E., \& Baumeister, R. F. (2005). Parenting behavior and adolescent behavioral and emotional problems: the role of self-control. International Journal of Behavioral Development, 29 (1), $58-69$.

[23] Tangney, J. P., Baumeister, R. F., \& Boone, A. L. (2004). High self-control predicts good adjusment, less pathology, better grades, and interpersonal success. Journal of Personality, 72 (2), 271 - 324.

[24] Vazsonyi, A. T., Pickering, L. E., Junger, M., \& Hessing, D. (2001). An empirical test of general theory of crime: a four-nation comparative study of self-control and the predicting of deviance. Journal of Research in Crime and Delinquency, 38 (2), 91 - 131.

[25] Eisenberg, N., \& Spinrad, T. L. (2004). Emotion-related regulation: sharpening the definition. Journal of Child Development, 75 (2), $334-339$.

[26] Rothbart, M. K., Ellis, L. K., Rueda, M. R., \& Posner, M. I. (2003). Developing mechanism of temperamental effortful control. Journal of Personality, 71 (6), 1113 - 1143.

[27] Rueda, M. R., Rothbart, M. K., \& Posner, M. I. (2005). The development of executive attention: contributions to the emergence of self-regulation. Journal of Development Neuropsychology, 28 (2), $573-594$.

[28] Wills, T. A., \& Dishion, T. J. (2004). Temperament and adolescence substance use: a transactional analysis of emerging self-control. Journal of Clinical Child Adolescence Psychology, 33 (1), 69 - 81.

[29] Eisenberg, N. (2017). What's in a word (or words): commentary on nigg (2017). On the relations among self-regulation, self-control, executive functioning, effortful control, cognitive control, impulsivity, risktaking, and inhibition for developmental psychopathology. Journal of Child Psychology and Psychiatry and Allied Disciplines, 58, $384-386$.

[30] Purwono, U., French, D. C., Eisenberg, N., \& Christ, S. (2018). Reliogisity and effortful control as 
predictors of antisocial behavior in muslim indonesian adolescents: moderation and mediation models. Psychology of Religion and Spirituality, Advance Online Publication.

[31] Corey, G. (2013). Teori dan Praktek Konseling dan Psikoterapi. Bandung: PT. Refika Aditama.

[32] Karp, M., Holmes, P., \& Tauvon, K. B. (1998). The Handbook of Psychodrama. London \& New York: Routledge.

[33] Bandura, A., Caprara, G. V., Barbaranelli, C., Gerbino, M., \& Pastorelli, C. (2003). role of affective selfregulatory efficacy in diserve spheres of psychosocial functioning. Journal of Child Development, 74 (3), $769-782$.

[34] Baumeister, R. F., \& Vohs, K. D. (2011). Handbook of Self-Regulation: Research, Theory, and Application. New York: The Guilford Press.

[35] Kelinger, F. N. (1996). Asas-asas Penelitian Behavioral ( $3^{\text {rd }}$ ed.). Yogyakarta: Gadjah Mada University Press.

[36] Hauser, J. D., Ellsworth, P. C., \& Gonzalez, R. (2018). Are manipulation checks necessary?. Frontiers in Pschology, 9 (1), 1 - 10.

[37] Achenbach, T.M. (1991). Manual for the Youth Self- Report and 1991 Profile. Burlington, VT: University of Vermont, Department of Psychiatry.

[38] Hurlock, E.B. (2012). Psikologi Perkembangan, Suatu Pendekatan Sepanjang Rentang Kehidupan (terjemahan). Jakarta: Erlangga.

[39] Santrock, J. W. (2012). Life Span Development (13 ${ }^{\text {th }}$ ed. Jilid I). Jakarta: Erlangga.

[40] Moser, C. A., \& Kalton, G. (1992). Survey Methods in Social Investigation ( $2^{\text {nd }}$ Edition). Aldershot, UK: Gower.

[41] Grinnell, R. M., \& Unrau, Y. A. (2011). Social Work Research and Evaluation. Foundation of EvidenceBased Practice. New York: Oxford University Press, Inc.

[42] Seniati, L., Yulianto, A., \& Setiadi, B. N. (2005). Psikologi Eksperimen. Jakarta: PT. Indeks.

[43] Piquero, A. R., Jennings, W. G., Farrington, D. P., Diamond, B., \& Gonzalez, J. M. R. (2016). A metaanalysis update on the effectiveness of early self-control improvement programs to improve self-control and reduce delinquency. Journal of Experimental Criminology, 12 (2), 249 - 264.

[44] Clemmer, D. (2006). The Prison Community. Berkeley: University of California Press.

[45] Roberton, T., Daffern, M., \& Bucks, R. S. (2014). Maladaptive emotion regulation and aggression in adult offenders. Journal of Psychology, Crime \& Law, 20 (10), 933 - 954.

[46] Baumeister, R. F., Gailliot, M., DeWall, C. N., \& Oaten, M. (2006). Self-regulation and personality: how interventions increase regulatory success, and how depletion moderates the effects of traits on behavior. Journal of Personality, 74 (6), 1773 - 1802.

[47] Gullota, T. P., \& Adams, G. R. (2005). Handbook of Adolescent Behavioral Problems: Evidence-Based Approaches to Prevention and Treatment. New York: Springer.

[48] Gardner, T. W., Dishion, T. J., \& Connell, A. M. (2008). Adolescent self-regulation as resilience: resistance to antisocial behavior within the deviant peer context. Journal Abnormal Child Psychology, 36, $273-284$.

[49] Dane, A. V., \& Marini, Z. A. (2014). Overt and relational forms of reactive aggression in adolescents: relations with temperamental reactivity and self-regulation. Personality and Individual Differences, 60, $60-66$. 